\title{
A theoretical survey of the ability of nanocarbon layers to deliver anti-cancer drug temozolomide to the target cancer cells
}

\author{
Saba Hadidi ${ }^{\mathrm{a}, \mathrm{b}^{*}}$, Farshad Shiri ${ }^{\mathrm{a}, \mathrm{b}}$, Mohammadsaleh Norouzibazaz $^{\mathrm{c}, \mathrm{d}}$ \\ ${ }^{a}$ Department of Chemistry, Faculty of Science, Razi University, Kermanshah, Iran \\ ${ }^{b}$ Medical Biology Research Center (MBRC) Kermanshah University of Medical Sciences, Kermanshah, Iran \\ ${ }^{c}$ Nano Science and Technology Research Center, Razi University, Kermanshah, Iran \\ ${ }^{d}$ Department of Organic Chemistry, Faculty of Chemistry, Razi University, Kermanshah, Iran \\ C H R O N I C L E \\ Article history: \\ Received November 21, 2018 \\ Received in revised form \\ November 21, 2018 \\ Accepted December 18, 2018 \\ Available online \\ December 19, 2018 \\ Keywords: \\ Temozolomide \\ Drug delivery \\ Carbon nano layers \\ C (sp2)

\begin{abstract}
A B S T R A C T
Density functional theory with the basis set of $6-31+\mathrm{G}(\mathrm{d})$ was used to investigate on the carbon nano layers, $\mathrm{C}(\mathrm{sp} 2)$, potential as a drug delivery system for transferring of anti-cancer drug temozolomide to the target tissue. In order to elucidate the possibility of drug transmission by utilizing a carrier, the mechanisms of direct drug degradation, and loaded drug on the carrier are analyzed and examined completely. Two possible and different pathways for direct drug hydrolysis have been considered. According to obtained results activation barriers of these two pathways are 62.17 and $72.10 \mathrm{kcal} \mathrm{mol}^{-1}$, and 64.30 and $70.10 \mathrm{kcal} \mathrm{mol}^{-1}$ for two gas mode and also two aqueous solvent conditions respectively. By comparison of outcomes, it can be found out that these activation barriers for both degradation pathways are significantly greater than the activation barriers for drug separation from the surface of carbon carrier (18.59 and 51.92 $\mathrm{kcal} \mathrm{mol}^{-1}$ for gas mode and 11.79 and $44.67 \mathrm{kcal} \mathrm{mol}^{-1}$ for aqueous solvent). Therefore, by studying the achieved outcomes, it can be deduced that separation and releasing of the drug from the carrier occurs faster kinetically than direct degradation of temozolomide, so the drug can reach to the target before direct decomposition.
\end{abstract}

(C) 2019 by the authors; licensee Growing Science, Canada.

\section{Introduction}

One of the significant issues which attract the attention of researchers is finding the new and efficient drug delivery systems. The affection of cancer chemotherapy is restricted by intense detrimental side effects induced by anticancer drugs and the incapability of drugs to access tumor sites specifically. ${ }^{1-3}$ In order to decrease the harmful and dangerous cytotoxic effect on healthy organs and destruct the cancerous cells with minimum harm to normal body tissue special drug delivery systems targeted specifically to cancer cells can be applied. ${ }^{4-10}$ Using an appropriate drug delivery system can contribute to patients to be cured better and faster. Nowadays various sorts of drug delivery systems are available and applied. ${ }^{11,12}$ Nanomaterials such as carbon nanotubes (CNT) and fullerenes are suitable materials and effective tools for drug delivery and transporting drug, molecules and other materials. ${ }^{13}$ Application and role of CNTs for the delivery of drugs to their special site of action has become one of the principals

\footnotetext{
* Corresponding author.

E-mail address: saba.hadidi@yahoo.com (S. Hadidi)

(C) 2019 by the authors; licensee Growing Science, Canada

doi: $10.5267 /$ j.ccl.2018.012.004
} 
and significant areas of interest for a large number of researchers and specialists. This significant role is mostly due to the characteristics of these materials, including their unique chemical and physical properties, a nano needle shape, hollow monolithic structure, and their capability to obtain the favorable functional groups on their outer layers. ${ }^{14-16}$ One of the important advantages of the CNT is its capability to deliver drugs directly to damaged organs and cancer cells. ${ }^{17}$ Another important and useful application of CNTs for drug delivery is intravenous injection. One of the problems with injecting drugs into the body is the hazard of blood vessels becoming blocked due to the large size of the drugs, which would lead to tissue toxicity and detrimental effects on organs. It has been offered that CNTs could be applied as nano carriers for delivering drugs into the body via injectable paths. ${ }^{17-19}$ Many benefits obtain from CNTs, but alongside the positives, they have some drawbacks. One of the principals and serious concerns for researchers is toxicity of nanoparticles. ${ }^{20,21}$ One of the suitable and efficient methods to make these materials less toxic and more biocompatible is the functionalization process. According to some investigations, the attachment of appropriate molecules and materials to the CNT surface can decline the toxicity of CNTs. ${ }^{22,23}$ These materials can be functionalized with different sort of agents such as proteins, peptides, nucleic acids and drugs, and applied to deliver their cargos to targets. ${ }^{24-26}$ These functionalized nanomaterials can transport their cargos across cell membranes with little cytotoxicity. ${ }^{27,} 28$ Also, nanomaterials have another privilege; they have a very high surface area per unit weight for high drug loading. ${ }^{7,29-32}$ The noncovalent interaction of doxorubicin which is an anticancer medicine, with CNTs have been investigated by Ali-Boucetta and co-worker and its cytotoxic activity has been studied. ${ }^{33}$ Various ways and methods have been utilized in order to load

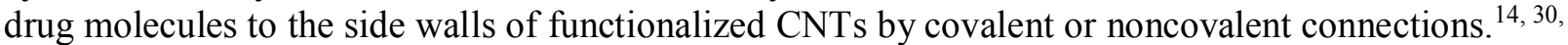
${ }^{34}$ Temozolomide (Fig. 1) which is known as an alkylating agent can be applied for the treatment of a wide spectrum of malignant, gliomas. ${ }^{35-40}$ The activation mechanism of temozolomide was reported by M. F. G. Stevens and co-workers and has been declared that the mechanism of degradation vary depends on $\mathrm{pH}$. The rate of temozolomide degradation enhances with an increase in $\mathrm{pH} .{ }^{41}$ The ringopening of temozolomide have been investigated by A. A. Taherpour and co-workers, ${ }^{42}$ and two different pathways for the ring-opening reaction have been considered, in addition, the protonation of all possible sites were studied in order to show the significant role of acidic conditions on the increased stability and mechanism of the medicine. The obtained outcomes have illustrated the preferable site for protonation is the oxygen of the amide group that would stabilize the system more than the next favourable protonation site. ${ }^{43}$ This article aims to elucidate the capability of nano carbon layers as drug delivery base. We have investigated the ability of nano carbon layers ( $\mathrm{sp}^{2}$ carbons) to deliver anticancer drug temozolomide to the target. Temozolomide was linked to carbon layers carrier and degradation mechanism under both neutral and acidic conditions have been studied in order to show that degradation of the drug would happen before or after reaching to target.

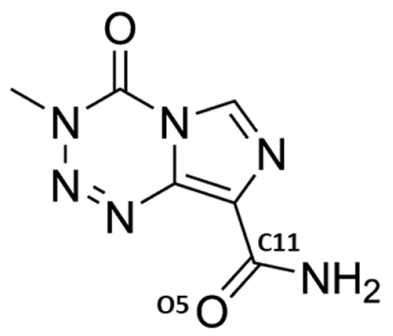

Fig. 1. Temozolomide structure

\section{Computational Details}

The complete geometrical optimization of all structures and transition states has been carried out with density functional theory ${ }^{44,45}$ by using the B3LYP ${ }^{46}$ functional and the $6-31+\mathrm{G}(\mathrm{d})$ basis set. To confirm that the systems are at a minimum point or transition state of potential energy surface, all the systems were confirmed by vibrational frequency calculations in the same basis set. Calculations of intrinsic reaction coordinates (IRC) ${ }^{47}$ were also performed on transition states to confirm that such structures are indeed connecting two minima. The computation was carried out for water as the solvent 
utilizing the SM8 (SCRF) model. ${ }^{48,49}$ All the analysis of molecular orbital composition, bond order analysis, and spin density analysis are performed on the .chf format of Multiwfn package. ${ }^{50}$ All the calculations were performed with ORCA, ${ }^{51}$ and Spartan 10 software suite of programs. ${ }^{52}$

\section{Results and discussion}

In this study, the potential of temozolomide drug transfer to the target by applying the $\mathrm{sp}^{2}$ carbon base has been analyzed. This survey can be performed by studying the following subjects and under various $\mathrm{pH}$ conditions. I. Investigation of hydrolysis process of the loaded drug on $\mathrm{CF}-\mathrm{C}\left(\mathrm{sp}^{2}\right)$ (Carboxylic group Functionalized on $\mathrm{C}\left(\mathrm{sp}^{2}\right)$ ) under acidic and neutral $\mathrm{pH}$ conditions; due to the interactive agent group of amine on temozolomide for interaction with the $\mathrm{CF}-\mathrm{C}\left(\mathrm{sp}^{2}\right)$; this part is investigated by studying of hydrolysis process of the amine groups ( $\mathrm{R}-\mathrm{NH}_{2}$ components) from the carboxylic site of CF-C $\left(\mathrm{sp}^{2}\right)$. II. Selection of optimized conditions with minimum activation barrier for amine hydrolysis in the previous step and examination of different degradation mechanisms of temozolomide from $\mathrm{CF}-\mathrm{C}\left(\mathrm{sp}^{2}\right)$ under selected $\mathrm{pH}$ condition. III. Study of the activation barrier for hydrolysis and decomposition of temozolomide without the presence of a carrier substrate for possible paths of direct drug degradation. IV. Potential determination of drug transfer by $\mathrm{CF}-\mathrm{C}\left(\mathrm{sp}^{2}\right)$ with comparison of activation energies in stages II and III; if the required energy for drug degradation is lower than the amount of this energy for separation from the $\mathrm{CF}-\mathrm{C}\left(\mathrm{sp}^{2}\right)$ base, the drug would be decomposed just before leaving the $\mathrm{CF}-\mathrm{C}\left(\mathrm{sp}^{2}\right)$, and so the $\mathrm{CF}-\mathrm{C}\left(\mathrm{sp}^{2}\right)$ base does not have the high capability to transfer drug to the target tissue. In contrast, if the required energy for drug degradation is greater than the amount of this energy to separate from the $\mathrm{CF}-\mathrm{C}\left(\mathrm{sp}^{2}\right)$ base, the drug is able to separate from the $\mathrm{CF}-\mathrm{C}\left(\mathrm{sp}^{2}\right)$ at lower energies and this can be a guarantee of transferring of the drug before of hydrolysis.

\subsection{Study of hydrolysis mechanism of $\mathrm{R}-\mathrm{NH}_{2}$ component connected to $\mathrm{CF}-\mathrm{C}\left(\mathrm{s} \mathrm{p}^{2}\right)$}

Drugs and materials with active amine group which have interaction with a carboxylic agent on CF$\mathrm{C}\left(\mathrm{sp}^{2}\right)$ surfaces can be hydrolyzed and separated from $\mathrm{CF}-\mathrm{C}\left(\mathrm{sp}^{2}\right)$ under various $\mathrm{pH}$ conditions. ${ }^{53}$ Due to the physiological buffering environment, hydrolysis generally occurs in neutral conditions, but studies have shown that in special parts of damaged tissues such as cancer cells, the situation is different and $\mathrm{pH}$ is lower than neutral rang and located in the acidic region. ${ }^{54,55}$ Therefore, drugs which are utilized to transfer to these special parts should have the ability to release their active component in these acidic tissues. The main purpose of this study is to investigate the transfer potential of temozolomide drug under acidic and neutral conditions. In order to generalize the work and with respect to the active amine group in temozolomide drug, in the first section, the hydrolysis potential of amine groups from the carboxylic acid agent is generally investigated and the effects of acidic and neutral conditions on the hydrolysis of these compounds are examined. Hydrolysis of [CF-( $\left.\left.\mathrm{sp}^{2}\right)\right]-\mathrm{RNH}_{2}$ under two neutral and acidic conditions has been summarized in Scheme 1. In both conditions, the reactions can be accomplished by passing through two transition states and intermediates leads to hydrolysis of amine group on the CF-C $\left(\mathrm{sp}^{2}\right)$ base (Fig. 2). Under the neutral condition, water molecule attack to the carbon of the carbonyl group and by passing through two transition states (N-TS-I and N-TS-II), the drug is separated from $\mathrm{CF}-\mathrm{C}\left(\mathrm{sp}^{2}\right)$. The value relative Gibbs free energy barrier in gas and aqueous phases for N-TS-II are 52.4 and $56.9 \mathrm{kcal} \mathrm{mol}^{-1}$ respectively. This separation in aqueous phase has more activation barrier energy $\left(4.3 \mathrm{kcal} \mathrm{mol}^{-1}\right)$ compared to the gas phase. Also, this separation under acidic condition by protonation of oxygen of the carbonyl group has been studied.

Based on Fig. 2. hydrolysis under acidic condition passes through two transition states H+TS-I and $\mathrm{H}+\mathrm{TS}-\mathrm{II}$ that H+TS-II has the most activation barrier with 39.2 and $49.156 .9 \mathrm{kcal} \mathrm{mol}^{-1}$ in gas and aqueous phases respectively. By comparison of activation barriers in neutral and acidic conditions, it can be concluded that acidic conditions decrease significantly the values of activation barriers by 93.4 in the gas phase and 7.9 in the aqueous phase. This outcome is because of the catalytic role of hydrogen on carbon of carbonyl group. ${ }^{56}$ Due to the connection of hydrogen to carbon this site would be activated compared to the neutral condition. 


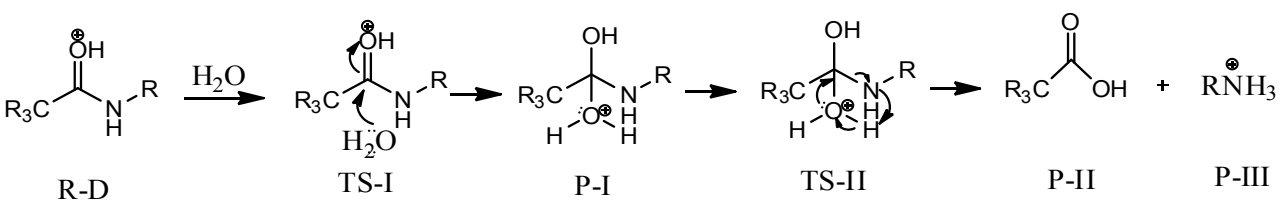

Acidic condition

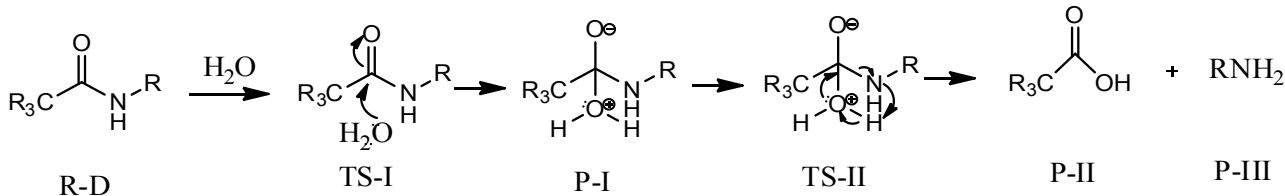

Neutral condition

Scheme 1. Degradation mechanism of $\mathrm{R}_{3} \mathrm{C}(\mathrm{CO}) \mathrm{NH}_{2}$ compounds at neutral and acidic conditions

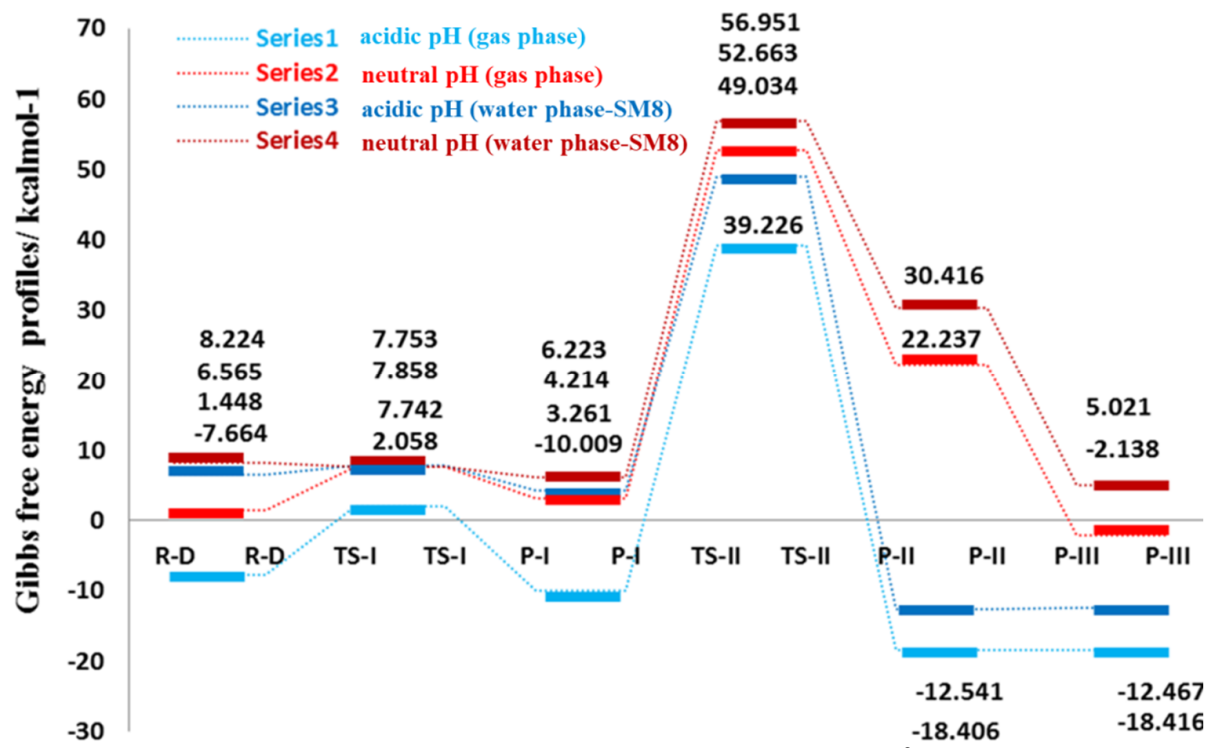

Fig. 2. Gibbs free energy profiles for connected $\mathrm{R}-\mathrm{NH}_{2}$ compounds to $\mathrm{sp}^{2}-\mathrm{FG}$ carbon layers decomposition pathways in the gas and SM8 models. (The abbreviation symbols (R-D, P-I etc...) are indicated in Schema 1)

\subsection{Degradation mechanism of connected temozolomide to $C F-C\left(s p^{2}\right)$ in two possible pathways and at acidic condition}

There are two possible protonation sites (O1 and $\mathrm{O} 5)$ on connected drug to the $\mathrm{CF}-\mathrm{C}\left(\mathrm{sp}^{2}\right)$ (Fig. 3). Therefore, we investigate the degradation of the drug when these two sites are protonated. So the degradation mechanism of linked temozolomide to $\mathrm{CF}-\left(\mathrm{sp}^{2}\right)$ can be studied in the following two ways. I. when O1 is protonated and II. when O5 is protonated (Scheme 2 and Fig. 4.).

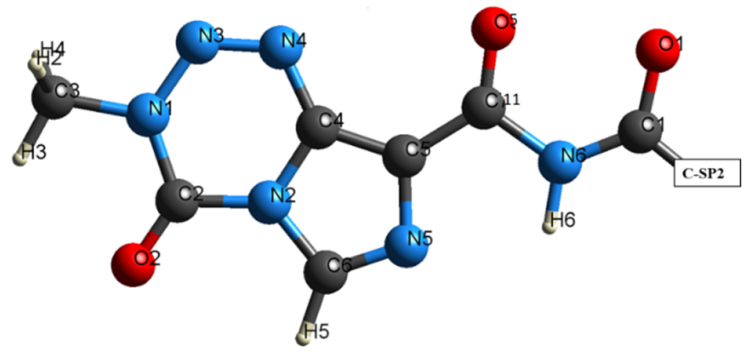

Fig. 1. Connected temozolomide to $\mathrm{C}\left(\mathrm{sp}^{2}\right)$ 
O1 protonated

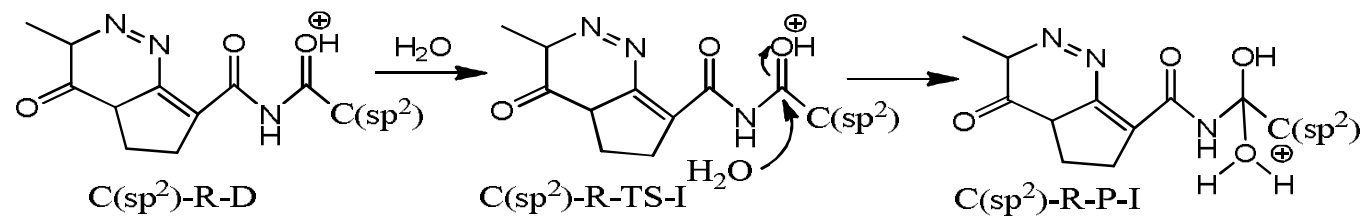

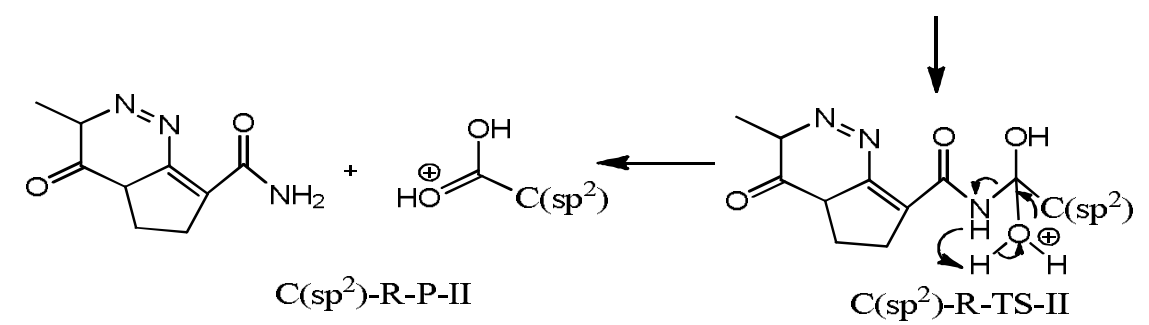

O5 protonated

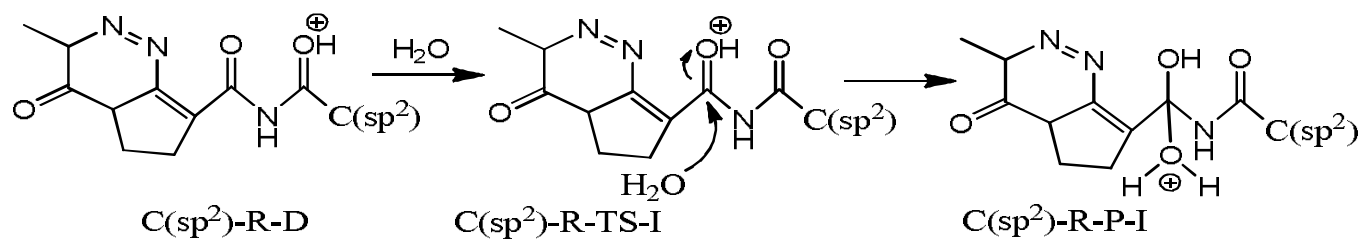
$\mathrm{C}\left(\mathrm{sp}^{2}\right)-\mathrm{R}-\mathrm{D} \quad \mathrm{C}\left(\mathrm{sp}^{2}\right)-\mathrm{R}-\mathrm{TS}-\mathrm{I}$ C(sp $\left.{ }^{2}\right)-R-P-I$

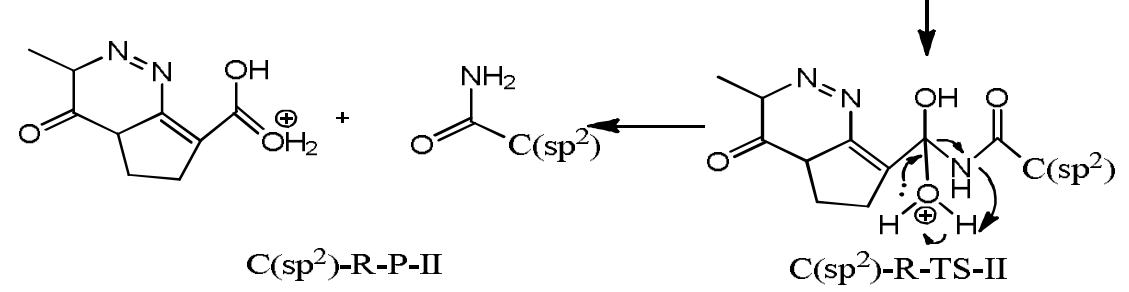

Scheme 2. Degradation mechanism of connected temozolomide to $C\left(\mathrm{sp}^{2}\right)-\mathrm{FG}$ carbon layers in two possible pathways at acidic condition.

In the first case when $\mathrm{O} 1$ site is protonated, proton $\left(\mathrm{H}^{+}\right)$is located on carboxyl which is attached to the $\mathrm{CF}-\mathrm{C}\left(\mathrm{sp}^{2}\right)$ base. Due to this action, carbon site of this group would be activated and the electrophilicity potential of this site reaches to $116.22 \mathrm{kcal} \mathrm{mol}^{-1}$ which has $13 \mathrm{kcal} \mathrm{mol}^{-1}$ more electrophilicity potential comared to the carbon site of the second carbonyl at C14 with $103.22 \mathrm{kcal}$ $\mathrm{mol}^{-1}$ (support information, SI 8). The main reason for increasing of electrophilicity potential is a major transfer of LUMO orbital portion from $0.00 \%$ to $51.01 \%$ at $\mathrm{C} 1$ and activation of this site for water attack (SI 10). This value of potential leads the reaction to attack to this site kinetically and the attack of a water molecule to this site would be facilitated. Due to this attack electron density transfers from double bond to $\mathrm{OH}^{+}$group and $\mathrm{O} 1 \mathrm{sp}^{2}$-R-TS-I with the energy of $9.08 \mathrm{kcal} \mathrm{mol}^{-1}$ is generated. This transition state with the complete transmission of electron density from double bond to $\mathrm{OH}$ and attachment of water molecule creates transition state of $\mathrm{O} 1 \mathrm{sp}^{2}$-R-P-I with an energy value of $3.18 \mathrm{kcal}$ $\mathrm{mol}^{-1}$.

This transition state is unstable and by some simultaneous transfers (simultaneous transfer of O-H at water molecule to oxygen and transmission of created O-C bond to carbon and finally, the transfer of N-C electron density to the nitrogen atom) by passing through O1 $\mathrm{sp}^{2}$-R-TS-II with energy of 18.59

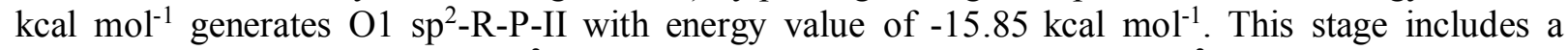
separated drug from the $\mathrm{CF}-\mathrm{C}\left(\mathrm{sp}^{2}\right)$ base. Due to this separation, the $\mathrm{CF}-\mathrm{C}\left(\mathrm{sp}^{2}\right)$ base is separated with a protonated hydroxide agent. By analyzing the effect of the water solvent on O1 $\mathrm{sp}^{2}$-R-TS-II, we can observe the energy reduces to $11.79 \mathrm{kcal} \mathrm{mol}^{-1}$. Since this transition state is the rate determining step, it can be clearly concluded that the aqueous solvent has a significant role on the reaction rate and can 
reduce the activation barrier energy. On the other hand, the effect of adding solvent on the product is reversed and leads to increasing the energy to $-11.72 \mathrm{kcal} \mathrm{mol}^{-1}$. The reason for this behavior maybe is the difference between compound solvation before and after degradation.

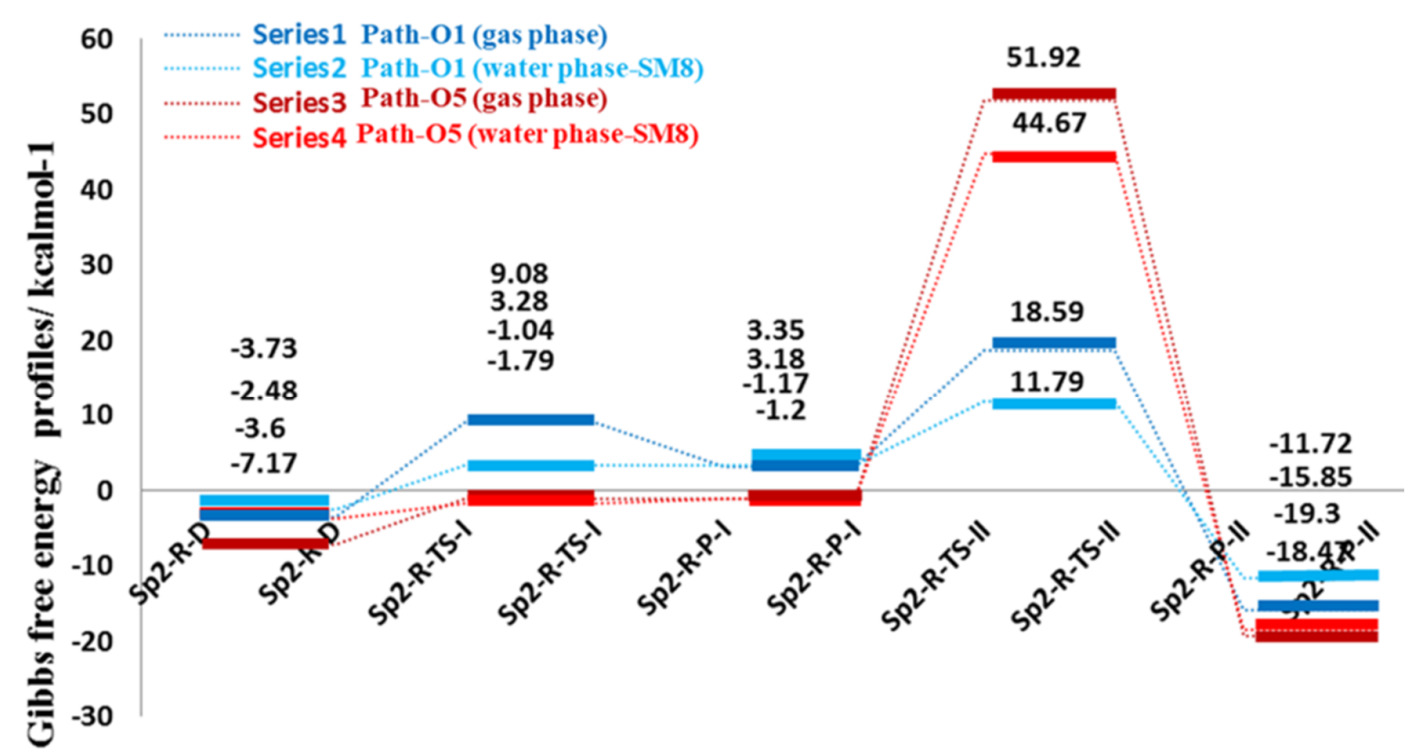

Fig. 4. Gibbs free energy profiles for connected temozolomide to $\mathrm{C}\left(\mathrm{sp}^{2}\right)-\mathrm{FG}$ carbon layers decomposition pathways in the gas and SM8 models. (The abbreviation symbols are indicated in Scheme 2)

The second path takes place with protonation of $\mathrm{O} 5$ which is related to the temozolomide carboxyl group, and adding of proton agent to this site can enhance electrophilicity potential about $4.65 \mathrm{kcal}$ $\mathrm{mol}^{-1}$ relative to the carbon of carbonyl 1 (SI 4). It is noteworthy that potential of attack declines compared to the previous case and this is because of the transfer of lower LUMO orbital portion to carbon site 14 which only increases $0.28 \%$ (SI 6). This low potential is capable to change the trend of attack in the previous mechanism. Similar to the previous path by an attack of water and passes thorough O5 $\mathrm{sp}^{2}$-R-TS-I transition state with $-1.04 \mathrm{kcal} \mathrm{mol}^{-1}$ energy, electron density transfers from carboxyl double bond to $\mathrm{OH}^{+}$group and by water attachment to this site, O5 $\mathrm{sp}^{2}-\mathrm{R}-\mathrm{P}-\mathrm{I}$ transition state with $-1.20 \mathrm{kcal} \mathrm{mol}^{-1}$ of energy is generated. This transition state by providing energy of $51.92 \mathrm{kcal}$ $\mathrm{mol}^{-1}$ and by passing through O5 $\mathrm{sp}^{2}$-R-TS-II (during transfer of $\mathrm{O}-\mathrm{H}$ bond to positive oxygen at the water then density transfer of $\mathrm{O}-\mathrm{C}$ related to water to $\mathrm{C}-\mathrm{OH}$ bond and separation of $\mathrm{C}-\mathrm{N}$ bond) reaches to product O5 $\mathrm{sp}^{2}$-R-P-II with $-19.30 \mathrm{kcal} \mathrm{mol}^{-1}$. The important point is the impact of water solvent on the second transition state which is the rate determining step and at model, SM8 decreases to the energy of $44.67 \mathrm{kcal} \mathrm{mol}^{-1}$. The significant point in this mechanism is that with advancement of separation, the drug is hydrolysed and separated along with the carboxylic agent and the decomposed materials do not include the initial state of the drug. So by this way, the decomposed material has a negative effect on drug performance, and not only does not make effective drug transfer but also reduces the initial dosage. By comparison of activation barrier energies of rate determining step of two pathways, it is absolutely clear that with protonation of $\mathrm{O} 1$ activation barrier for gas phase $18.59 \mathrm{kcal} \mathrm{mol}^{-1}$ and for aqueous solvent $11.79 \mathrm{kcal} \mathrm{mol}^{-1}$ are obtained that would stabilize about $33.33 \mathrm{kcal} \mathrm{mol}^{-1}$ in gas mode and $32.88 \mathrm{kcal} \mathrm{mol}^{-1}$ in water solvent mode relative to $\mathrm{O} 5$ protonated and the reaction occurs faster kinetically.

Both of these activation barriers can be compared with activation barrier of direct drug hydrolysis which for gas mode and water solvent are $62.17 \mathrm{kcal} \mathrm{mol}^{-1}$ and $64.30 \mathrm{kcal} \mathrm{mol}^{-1}$ respectively and for path 2 obtained activation barrier are $72.10 \mathrm{kcal} \mathrm{mol}^{-1}$ and $70.17 \mathrm{kcal} \mathrm{mol}^{-1}$ for gas mode and water solvent respectively (Fig. 5 and Scheme 3). By comparison of the activation barriers of drug decomposition with activation barriers of drug separation (from $\mathrm{CF}-\mathrm{C}\left(\mathrm{sp}^{2}\right)$ ), it is clear, that separation should be more energetically favorable than decomposition. This indicates that before the separation 
drug may not undergo the decomposition from the carbon base, and will be transmitted by the CNTbase to the target.
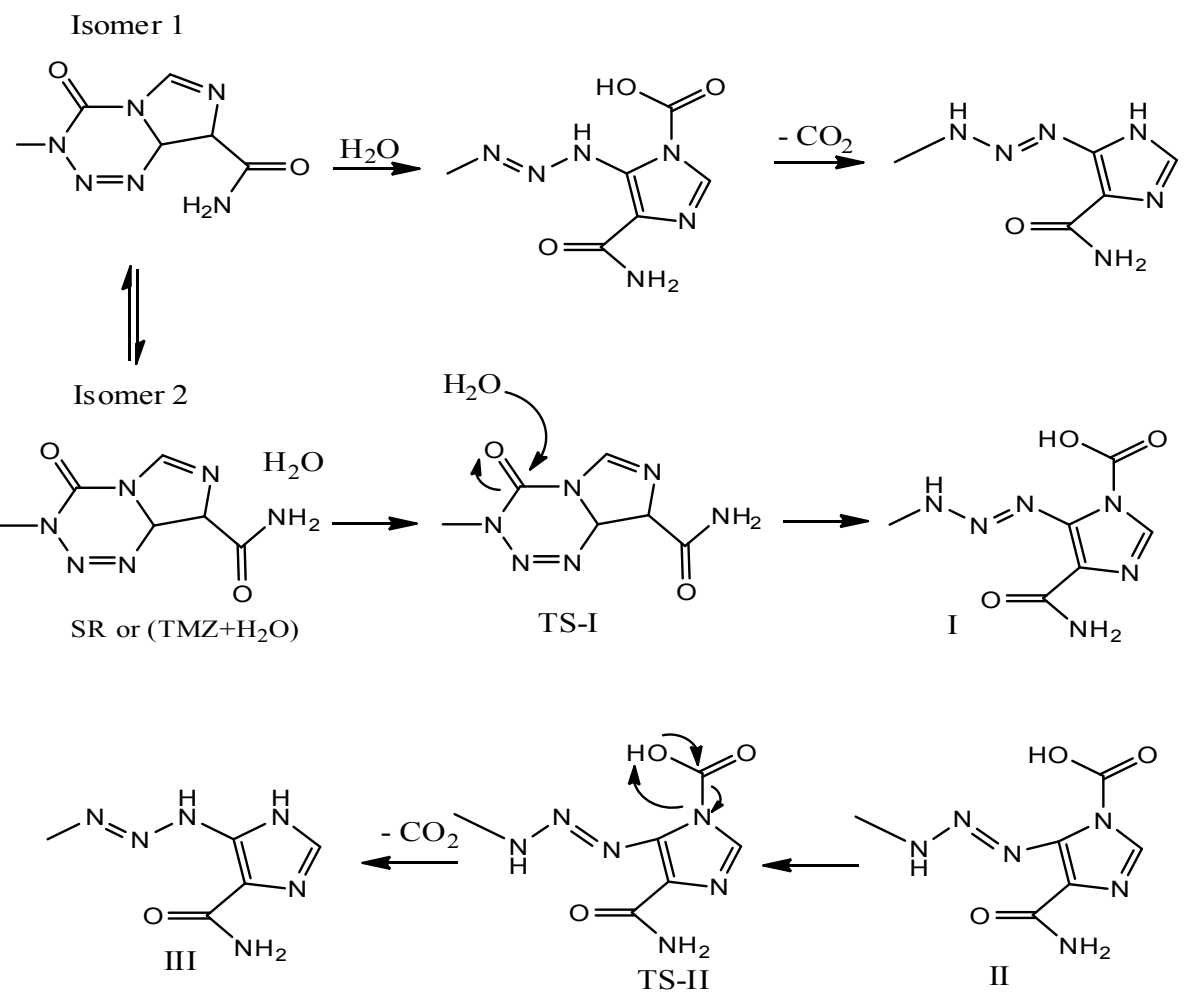

Scheme 3. The different pathways for the direct hydrolysis of temozolomide

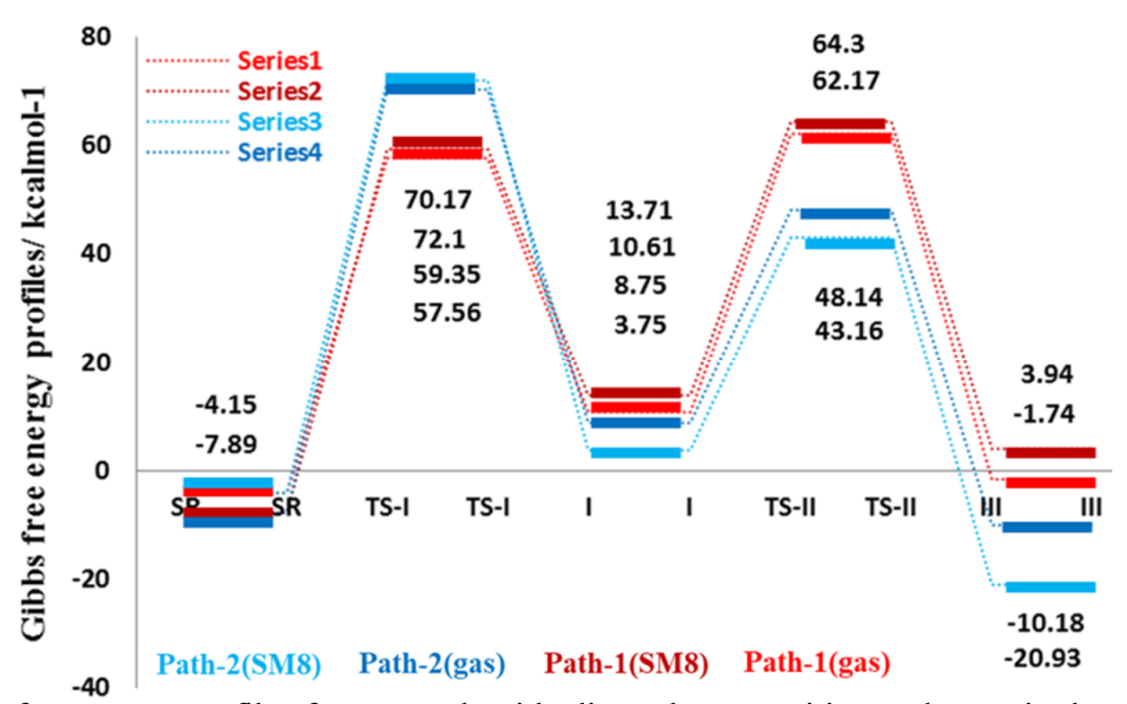

Fig. 5. Gibbs free energy profiles for temozolomide direct decomposition pathways in the gas and SM8 models. (The abbreviation symbols are indicated in Schema 3)

\section{Conclusion}

We have performed DFT calculations for carbon nano layers $\mathrm{C}\left(\mathrm{sp}^{2}\right)$ in order to clarify their role as a nanocarrier for drug delivery of anti-cancer drug temozolomide. To compare mechanisms of direct temozolomide degradation and the separation of drug from carrier, possible mechanisms for each case have been investigated and analyzed. By comparison of the activation barriers of drug decomposition with activation barriers of drug separation $\left(\right.$ from $\mathrm{CF}-\mathrm{C}\left(\mathrm{sp}^{2}\right)$ ), it is clear that separation should be more 
energetically favourable than decomposition. This indicate, that the drug may not be decomposed before separation from the carbon base and will be transmitted by the base to the target. Also based on obtained outcomes, under the acidic condition, the drug separation from the carrier is faster than it direct degradation; therefore it could be expected that the $\mathrm{sp} 2$ carbon carrier can act as a suitable drug delivery vehicle, which has a potential and capability to transmit the anti-cancer drug temozolomide to the target tissue.

\section{Financial interest}

The authors declare no competing financial interest.

\section{Conflict of Interest}

The authors declare that they have no conflict of interest.

\section{Ethical approval}

This article does not contain any studies with human participants or animals performed by any of the authors.

\section{References}

1 Joseph J. S., Lam V., and Patel M. I. (2018) Preventing osteoporosis in men taking androgen deprivation therapy for prostate cancer: A systematic review and meta-analysis. European Urology Oncology.

2 Erdoğar N., and Bilensoy E. (2018) Cyclodextrin-based nanosystems in targeted cancer therapyCyclodextrin applications in medicine, food, environment and liquid crystals. Springer, 59-80.

3 Correa D., Root J., Kryza-Lacombe M., Mehta M., Karimi S., Hensley M., and Relkin N. (2017) Brain structure and function in patients with ovarian cancer treated with first-line chemotherapy: A pilot study. Brain imaging and behavior, 11 (6) 1652-1663.

4 Minko T. (2004) Drug targeting to the colon with lectins and neoglycoconjugates. Advanced drug delivery reviews, 56 (4) 491-509.

5 Minko T., Dharap S., Pakunlu R., and Wang Y. (2004) Molecular targeting of drug delivery systems to cancer. Current Drug Targets, 5 (4) 389-406.

6 Dhar S., Gu F. X., Langer R., Farokhzad O. C., and Lippard S. J. (2008) Targeted delivery of cisplatin to prostate cancer cells by aptamer functionalized pt (iv) prodrug-plga-peg nanoparticles. Proceedings of the National Academy of Sciences, 105 (45) 17356-17361.

7 Dhar S., Liu Z., Thomale J., Dai H., and Lippard S. J. (2008) Targeted single-wall carbon nanotube-mediated pt (iv) prodrug delivery using folate as a homing device. Journal of the American Chemical Society, 130 (34) $11467-11476$.

8 Liu Z., Chen K., Davis C., Sherlock S., Cao Q., Chen X., and Dai H. (2008) Drug delivery with carbon nanotubes for in vivo cancer treatment. Cancer research, 68 (16) 6652-6660.

9 Hughes G. A. (2017) Nanostructure-mediated drug deliveryNanomedicine in cancer. Pan Stanford, 47-72.

10 Wong C. R., Bawendi M. G., Fukumura D., and Jain R. K. (2018) Multistage nanoparticle drug delivery system for the treatment of solid tumors. Google Patents.

11 Maeda H. (2001) The enhanced permeability and retention (epr) effect in tumor vasculature: The key role of tumor-selective macromolecular drug targeting. Advances in enzyme regulation, 41 (1) 189-207.

12 Allen T. M. (2002) Ligand-targeted therapeutics in anticancer therapy. Nature Reviews Cancer, 2 (10) 750.

13 Bianco A., Kostarelos K., Partidos C. D., and Prato M. (2005) Biomedical applications of functionalised carbon nanotubes. Chemical Communications, (5) 571-577.

14 Sahoo N. G., Bao H., Pan Y., Pal M., Kakran M., Cheng H. K. F., Li L., and Tan L. P. (2011) Functionalized carbon nanomaterials as nanocarriers for loading and delivery of a poorly water-soluble anticancer drug: A comparative study. Chemical communications, 47 (18) 5235-5237.

15 Karki N., Tiwari H., Pal M., Chaurasia A., Bal R., Joshi P., and Sahoo N. G. (2018) Functionalized graphene 
oxides for drug loading, release and delivery of poorly water soluble anticancer drug: A comparative study. Colloids and Surfaces B: Biointerfaces, 169 265-272.

16 Pham-Huy C., Dramou P., Pham-Huy L. A., Xiao D., and He H. (2017) Carbon nanotubes used as nanocarriers in drug and biomolecule deliveryDrug delivery approaches and nanosystems, volume 1. Apple Academic Press, 163-212.

17 Beg S., Rizwan M., Sheikh A. M., Hasnain M. S., Anwer K., and Kohli K. (2011) Advancement in carbon nanotubes: Basics, biomedical applications and toxicity. Journal of pharmacy and pharmacology, 63 (2) 141163.

18 Jin H., Heller D. A., and Strano M. S. (2008) Single-particle tracking of endocytosis and exocytosis of singlewalled carbon nanotubes in nih-3t3 cells. Nano letters, 8 (6) 1577-1585.

19 Beg S., Rahman M., Jain A., Saini S., Hasnain M., Swain S., Imam S., Kazmi I., and Akhter S. (2018) Emergence in the functionalized carbon nanotubes as smart nanocarriers for drug delivery applicationsFullerens, graphenes and nanotubes. Elsevier, 105-133.

20 Berhanu D., Dybowska A., Misra S. K., Stanley C. J., Ruenraroengsak P., Boccaccini A. R., Tetley T. D., Luoma S. N., Plant J. A., and Valsami-Jones E. (2009) Characterisation of carbon nanotubes in the context of toxicity studies. Environmental Health, 8 (1) S3.

21 Bishop L., Cena L., Orandle M., Yanamala N., Dahm M. M., Birch M. E., Evans D. E., Kodali V. K., Eye T., and Battelli L. (2017) In vivo toxicity assessment of occupational components of the carbon nanotube life cycle to provide context to potential health effects. ACS nano, 11 (9) 8849-8863.

22 Fei B., Lu H., Hu Z., and Xin J. H. (2006) Solubilization, purification and functionalization of carbon nanotubes using polyoxometalate. Nanotechnology, 17 (6) 1589.

23 Coccini T., Roda E., Sarigiannis D., Mustarelli P., Quartarone E., Profumo A., and Manzo L. (2010) Effects of water-soluble functionalized multi-walled carbon nanotubes examined by different cytotoxicity methods in human astrocyte d384 and lung a549 cells. Toxicology, 269 (1) 41-53.

24 Bianco A., Kostarelos K., and Prato M. (2005) Applications of carbon nanotubes in drug delivery. Current opinion in chemical biology, 9 (6) 674-679.

25 Kostarelos K., Lacerda L., Partidos C., Prato M., and Bianco A. (2005) Carbon nanotube-mediated delivery of peptides and genes to cells: Translating nanobiotechnology to therapeutics. Journal of Drug Delivery Science and Technology, 15 (1) 41-47.

26 Bianco A. (2004) Carbon nanotubes for the delivery of therapeutic molecules. Expert opinion on drug delivery, 1 (1) 57-65.

27 Schipper M. L., Nakayama-Ratchford N., Davis C. R., Kam N. W. S., Chu P., Liu Z., Sun X., Dai H., and Gambhir S. S. (2008) A pilot toxicology study of single-walled carbon nanotubes in a small sample of mice. Nature nanotechnology, 3 (4) 216.

28 Singh R., Pantarotto D., Lacerda L., Pastorin G., Klumpp C., Prato M., Bianco A., and Kostarelos K. (2006) Tissue biodistribution and blood clearance rates of intravenously administered carbon nanotube radiotracers. Proceedings of the National Academy of Sciences of the United States of America, 103 (9) 3357-3362.

29 Ajima K., Yudasaka M., Murakami T., Maigné A., Shiba K., and Iijima S. (2005) Carbon nanohorns as anticancer drug carriers. Molecular pharmaceutics, 2 (6) 475-480.

30 Wu W., Wieckowski S., Pastorin G., Benincasa M., Klumpp C., Briand J. P., Gennaro R., Prato M., and Bianco A. (2005) Targeted delivery of amphotericin $b$ to cells by using functionalized carbon nanotubes. Angewandte Chemie International Edition, 44 (39) 6358-6362.

31 Lucío M. I., Opri R., Pinto M., Scarsi A., Fierro J. L., Meneghetti M., Fracasso G., Prato M., Vázquez E., and Herrero M. A. (2017) Targeted killing of prostate cancer cells using antibody-drug conjugated carbon nanohorns. Journal of Materials Chemistry B, 5 (44) 8821-8832.

32 Chandrasekhar P. (2018) Cnt applications in drug and biomolecule deliveryConducting polymers, fundamentals and applications. Springer, 61-64.

33 Ali-Boucetta H., Al-Jamal K. T., Mccarthy D., Prato M., Bianco A., and Kostarelos K. (2008) Multiwalled carbon nanotube-doxorubicin supramolecular complexes for cancer therapeutics. Chemical Communications, (4) 459-461.

34 Zhang L., Xia J., Zhao Q., Liu L., and Zhang Z. (2010) Functional graphene oxide as a nanocarrier for controlled loading and targeted delivery of mixed anticancer drugs. Small, 6 (4) 537-544.

35 Quirbt I., Verma S., Petrella T., Bak K., Charette M., and Care M. O. T. M. D. S. G. O. C. C. O. S. P. I. E.B. (2007) Temozolomide for the treatment of metastatic melanoma. Current Oncology, 14 (1) 27.

36 Van Den Bent M., Taphoorn M., Brandes A. A., Menten J., Stupp R., Frenay M., Chinot O., Kros J., Van Der Rijt C., and Vecht C. J. (2003) Phase ii study of first-line chemotherapy with temozolomide in recurrent oligodendroglial tumors: The european organization for research and treatment of cancer brain tumor group 
study 26971. Journal of clinical oncology, 21 (13) 2525-2528.

37 Friedman H. S., Kerby T., and Calvert H. (2000) Temozolomide and treatment of malignant glioma. Clinical cancer research, 6 (7) 2585-2597.

38 Kaur S., Ramdzan Z. M., Guiot M.-C., Li L., Leduy L., Ramotar D., Sabri S., Abdulkarim B., and Nepveu A. (2017) Cux1 stimulates ape1 enzymatic activity and increases the resistance of glioblastoma cells to the mono-alkylating agent temozolomide. Neuro-oncology, 20 (4) 484-493.

39 Tateishi K., Higuchi F., Miller J., Koerner M. V., Lelic N., Shankar G. M., Tanaka S., Fisher D. E., Batchelor T., and Iafrate A. J. (2017) The alkylating chemotherapeutic temozolomide induces metabolic stress in idh1mutant cancers and potentiates nad + depletion-mediated cytotoxicity. Cancer research, canres. 2263.2016.

40 Treggiari E., Elliott J., Baines S., and Blackwood L. (2018) Temozolomide alone or in combination with doxorubicin as a rescue agent in 37 cases of canine multicentric lymphoma. Veterinary and comparative oncology, 16 (2) 194-201.

41 Denny B. J., Wheelhouse R. T., Stevens M. F., Tsang L. L., and Slack J. A. (1994) Nmr and molecular modeling investigation of the mechanism of activation of the antitumor drug temozolomide and its interaction with DNA. Biochemistry, 33 (31) 9045-9051.

42 Mirzaei S., Taherpour A. A., and Khalilian H. (2018) Importance of azo-hydrazo tautomerization in the oxidative degradation of procarbazine by cytochrome p450: Computational insights. ChemistrySelect, 3 (22) 6042-6049.

43 Mirzaei S., Khalilian M., and Taherpour A. A. (2015) Mechanistic study of the hydrolytic degradation and protonation of temozolomide. RSC Advances, 5 (51) 41112-41119.

44 Becke A. D. (1993) Density-functional thermochemistry. Iii. The role of exact exchange. The Journal of chemical physics, 98 (7) 5648-5652.

45 Medvedev M. G., Bushmarinov I. S., Sun J., Perdew J. P., and Lyssenko K. A. (2017) Density functional theory is straying from the path toward the exact functional. Science, 355 (6320) 49-52.

46 Lee C. (1993) Yang, w and parr rg 1988 phys. Rev. B37 785;(b) becke ad. J. Chem. Phys., 1993, 98.

47 Hratchian H. P., and Schlegel H. B. (2005) Finding minima, transition states, and following reaction pathways on ab initio potential energy surfacesTheory and applications of computational chemistry. Elsevier, 195-249.

48 Miertuš S., Scrocco E., and Tomasi J. (1981) Electrostatic interaction of a solute with a continuum. A direct utilizaion of ab initio molecular potentials for the prevision of solvent effects. Chemical Physics, 55 (1) 117129.

49 Klamt A., Mennucci B., Tomasi J., Barone V., Curutchet C., Orozco M., and Luque F. J. (2009) On the performance of continuum solvation methods. A comment on "universal approaches to solvation modeling". Accounts of chemical research, 42 (4) 489-492.

$50 \mathrm{Lu} \mathrm{T}$., and Chen F. (2012) Multiwfn: A multifunctional wavefunction analyzer. J. Comput. Chem., 33 (5) 580-592.

51 Neese F., and Wennmohs F. (2013) Orca (3.0. 2)-an ab initio. DFT and semiempirical SCF-MO package,(Max-Planck-Institute for Chemical Energy Conversion Stiftstr. 34-36, 45470 Mulheim ad Ruhr, Germany).

52 Gunasekaran S., Balaji R. A., Kumeresan S., Anand G., and Srinivasan S. (2008) Experimental and theoretical investigations of spectroscopic properties of n-acetyl-5-methoxytryptamine. Can. J. Anal. Sci. Spectrosc, 53 149-160.

53 Morrison R., and Boyd R. (1992) Functional derivatives of carboxylicacids. Organic Chemistry, 821, 845.

54 Warburg O. (1956) On the origin of cancer cells. Science, 123 (3191) 309-314.

55 Griffiths J. (1991) Are cancer cells acidic? British journal of cancer, 64 (3) 425.

56 Burgi H., Dunitz J., and Shefter E. (1973) Geometrical reaction coordinates. Ii. Nucleophilic addition to a carbonyl group. Journal of the American Chemical Society, 95 (15) 5065-5067.

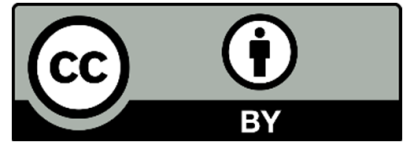

(C) 2018 by the authors; licensee Growing Science, Canada. This is an open access article distributed under the terms and conditions of the Creative Commons Attribution (CC-BY) license (http://creativecommons.org/licenses/by/4.0/). 